\title{
THREE-DIMENSIONAL THERMALHYDRAULIC ANALYSIS OF MOLTEN SALT REACTOR CONCEPTS
}

\author{
Bogdán Yamaji, Dr. Gyula Csom, Dr. Attila Aszódi \\ Institute of Nuclear Techniques, Budapest University of Technology and Economics
}

Partitioning and transmutation is expected to be a promising option to extend the possibilities of nuclear energy and give a good solution for the problem of high level radwaste. Several liquid-fueled reactor concepts or accelerator driven subcritical systems (ADS) were proposed as transmutors. Many of these consider fluoride based molten salts as the liquid fuel and coolant medium. The thermalhydraulic behavior of these systems is expected to be fundamentally different than the behavior of widely used water-cooled reactors with solid fuel. Considering large flow domains three-dimensional thermalhydraulic analysis seems to be applicable. Since the fuel is the coolant medium as well, one can expect a stronger coupling between reactor physics and thermalhydraulics, too. In the present paper the application of Computational Fluid Dynamics (CFD) for three-dimensional thermalhydraulics simulations of molten salt reactor concepts is introduced. First a homogenous single region molten salt reactor concept is studied and optimized. In this model the heat carrier/fuel salt is circulated through the core by external pumps. The nominal thermal output is $2500 \mathrm{MW}$. Another single region reactor concept is introduced as well. This concept has internal heat exchangers in the flow domain and the molten salt is circulated by natural convection. In the paper the results of the CFD calculations with these concepts are presented. In the further work our objective is to investigate the thermalhydraulics of the multi-region molten salt reactor.

Keywords: Molten salt reactor, thermalhydraulics, CFD, transmutation 